\title{
DEMOCRACIA, HOSPITALIDAD Y VIOLENCIA. ENTREVISTA CON MARC CRÉPON
}

\author{
Entrevista y traducción de \\ Verónica González y Javier Agüero Águila* \\ gp.veronica@gmail.com \\ jagueroag@gamail.com
}

Marc Crépon es director de investigación en el Centre National de la Recherche Scientifique (CNRS) y director del Departamento de Filosofía de l'École normale supérieure de París (ENS). Entre sus publicaciones se encuentran: La culture de la peur, I. Démocratie, identité, sécurité (Galilée, 2008); La culture de la peur, II. La guerre des civilisations (Galilée, 2010); Le consentement meurtrier (Cerf, 2012); La vocation de l'écriture (Odile Jacob, 2014); La gauche c'est quand?(Des Equateurs, 2015).

Verónica González: La entrevista se organiza en torno a tres ejes que nos parecen reunir las problemáticas políticas actuales que están presentes en su obra. El primer eje concierne a la democracia y la cultura del miedo; el segundo trata sobre la democracia y la hospitalidad; y el tercero sobre el vínculo entre política, violencia y lenguaje.

Usted ha escrito sobre el miedo, sobre una suerte de cultura del miedo que habría encontrado hoy día un terreno fértil para germinar y extenderse. En esta línea, usted plantea que los Estados democráticos transforman esta cultura volviéndola un principio de gestión y de administración del poder. La democracia tendría entonces la tendencia a confundirse con otros regímenes de los cuales quisiera, más bien, distinguirse y oponerse (por ejemplo, los totalitarismos). ¿Cómo cree que debería ser una democracia cuyo principio es neutralizar y oponerse a esta cultura del miedo?

Marc Crépon: La primera cosa que quisiera decir es que no se trata de diabolizar el miedo, porque el miedo es legítimo y existen objetivamente razones para tener miedo. Se puede distinguir, en efecto, diversos dominios de la existencia que son favorables al desarrollo e, incluso, a la progresión de esta emoción. Es legítimo tener miedo por la salud, por el estado del planeta, por el medio ambiente, etc. ¡Y qué decir del miedo a perder el empleo!, el miedo a estar cesante y, por lo tanto, el miedo a una cierta degradación social. Todos estos miedos que atraviesan las sociedades son miedos legítimos, sin contar los miedos reales ligados a la situación internacional, porque

Verónica González es doctoranda y becaria CONICYT del programa de Doctorado en Filosofía con mención en Estética y Teoría del Arte de la Universidad de Chile. Javier Agüero Águila es doctorando en Filosofía de la Universidad París 8, miembro del Laboratorio de estudios sobre las lógicas contemporáneas de la filosofía (LLCP) y becario CONICYT. 
vivimos en un mundo objetivamente amenazante. En consecuencia, no hay que hacerse una imagen exclusivamente peyorativa del miedo.

Ahora, dicho esto, es preciso analizar la forma en que los Estados democráticos administran el miedo del ciudadano, las emociones del ciudadano. Tradicionalmente hemos pensado que los regímenes no-democráticos se han apoyado siempre en el miedo, lo han mantenido, lo han cultivado, y siempre han hecho del miedo del ciudadano uno de los instrumentos de conservación del poder. Y, a la inversa, se pensaba que los regímenes democráticos se distinguían de los no-democráticos en que no tenían necesidad de este miedo para ejercer el poder. Lo que ha creado hoy una confusión es que los gobiernos democráticos han comprendido -lo que es más visible ahora- que podían instrumentalizar las emociones de los ciudadanos para consolidar su legitimidad. Ahora bien, esta instrumentalización es de geometría variable, porque ella consiste para los gobiernos democráticos, como se ha observado en los últimos años, en fabricar lo que el sociólogo Zygmunt Bauman llama "blancos de sustitución”. Esto implica para los gobiernos escoger, entre los diferentes miedos de los ciudadanos, aquellos que se transformarán en blanco -y de los cuales el gobierno mismo va a asegurar y declarar poder hacerse cargo- $\mathrm{y}$, por otro lado, aquellos miedos que no serán por completo de su incumbencia. De esta manera, los gobiernos podrán admitir que los ciudadanos tengan miedo de perder su trabajo, que teman a los efectos desastrosos que la mundialización tiene sobre el empleo, reconociendo el sentimiento de inseguridad que resulta de esto y confesando al mismo tiempo que no pueden hacer gran cosa contra esta inseguridad, ya que no tienen el control sobre los efectos de la mundialización. Es así que las sociedades democráticas ven desarrollarse un desempleo endémico, una pobreza creciente, sin que el miedo que se instala en los ciudadanos sea aquel del que los gobiernos se preocupan prioritariamente. De ahí entonces los blancos de sustitución tales como los extranjeros, los inmigrantes, los delincuentes. El fenómeno fue particularmente sensible en el último quinquenio, cuando el anterior presidente de la República en Francia, Nicolas Sarkozy, se dedicaba, cada seis meses, a ofrecer a la opinión pública un nuevo blanco de sustitución.

Entonces, lo que llamo la cultura del miedo consiste en dos cosas. Por una parte, en la fabricación de estos blancos de sustitución y, por otra, en el rechazo -frente a los miedos de los ciudadanos- a tomar partido por un discurso racional, y en mantenerse entonces permanentemente en las emociones de los ciudadanos en lugar de intentar corregirlas por un discurso de este orden.

Javier Agüero: Usted acaba de hablar de la figura de los inmigrantes, de los extranjeros, la que se encuentra también en el centro de su trabajo. Considerando esta problematización que usted ha realizado a propósito de la democracia y la cultura del miedo, nos parece que no hay una relación esencial entre democracia y hospitalidad, sino que, más bien, la hospitalidad es una exigencia-que como toda exigencia es externa- frente a la cual las democracias occidentales deben dar una respuesta. ¿Usted piensa, finalmente, que la democracia y la hospitalidad son dos instancias consubstanciales, o bien ellas están forzadas a encontrarse? 
M.C.: Para mí ellas son completamente consubstanciales, porque en el fondo lo que debería distinguir a la democracia de todos los otros regímenes políticos es que la pertenencia a la ciudadanía no está condicionada por ninguna otra forma de pertenencia, es decir, que para ser ciudadano de una democracia no se debiera tener en cuenta ninguna otra forma de pertenencia cualquiera ésta sea, de orden religioso, étnico, cultural, lingüístico, etc. Pienso que una democracia es un sistema político en el cual la pertenencia no está condicionada, aunque todas las formas de restricciones a la hospitalidad consisten, precisamente, en poner condiciones. Existe entonces un vínculo consubstancial entre democracia y hospitalidad, y pienso que hoy -para decir las cosas en otro sentidouna de las fuerzas más hostiles que amenaza a las democracias, particularmente a las democracias europeas, es la xenofobia que se desarrolla y que consiste en estigmatizar al extranjero, al refugiado, al inmigrante. La xenofobia trae consigo el despliegue de fuerzas políticas efectivamente reaccionarias, racistas, cuyos valores y principios son, desde mi punto de vista, absolutamente hostiles y contrarios a los de la democracia.

Creo, además, que los valores de la República-libertad, igualdad, fraternidaddefinen también los principios sobre los cuales deberían apoyarse las democracias europeas; y desde el momento en que se comienza a querer multiplicar las condiciones a la hospitalidad -cuando aceptamos que se instale progresivamente en la opinión pública una manera de hablar de los extranjeros, de los inmigrantes y de los refugiados como si fueran un problema y se les estigmatiza-, se vulneran estos valores fundamentales sobre los cuales reposa nuestro compromiso con la democracia y la República. Hoy día esta cuestión de la hospitalidad está en el corazón de lo que fragiliza las democracias europeas, así como la construcción de Europa, tal como se ha visto este verano con la crisis de los refugiados; porque ella se traduce en el creciente poder de fuerzas políticas cuya historia entera, toda su herencia, son contrarias no solamente a los valores de la República, sino igualmente a los de la democracia.

La democracia y la hospitalidad son consubstanciales, porque no se puede condicionar la pertenencia a la ciudadanía. En la esencia de la democracia hay algo que supone la hospitalidad, la acogida a los extranjeros, la apertura al otro. Este es el primer punto. Luego, ellas son consubstanciales, porque hoy día se trata de un combate político, y aquellos que son hostiles a esta apertura son los mismos que históricamente se han opuesto, en diferentes momentos de nuestra historia, a la democracia.

J.A.: ¿Podemos pensar que todos los que se oponen a acoger al extranjero son antidemócratas?

M.C.: Pienso que hay una incompatibilidad fundamental entre la xenofobia (concebida como el miedo al extranjero) y los valores que se le reclaman a las democracias. Esta es una posición que es preciso defender con mucha firmeza. 
J.A.: En su último debate con Alain Finkielkraut, titulado ¿Cómo se puede ser extranjero? ${ }^{1}$, que concierne al fenómeno de la integración de los inmigrantes, usted sostuvo algo que nos pareció, al menos, inquietante. Usted afirmó, intentando responder a los argumentos de Finkielkraut que por lo general son muy localizados según nuestra opinión, que Derrida no era el apóstol de la hospitalidad incondicional. Esto es interesante porque es cierto que Derrida piensa lo incondicional como una suerte de exigencia ética de lo condicional, o bien como algo que debería hacer presión sobre lo condicional, de tal manera que la dimensión política y las leyes mismas sean creadas considerando este espacio de lo incalculable y de lo hiperbólico. Sin embargo, en numerosos pasajes de la obra de Derrida se plantea que la hospitalidad incondicional debe permanecer pura, absoluta (El monolingüismo del otro, entre otros textos) y que no puede ser política ni reglada por la ley, y, en definitiva, que la hospitalidad incondicional no puede ser pública, todo salvo pública.

¿Cree finalmente que, más allá de lo condicional, Derrida no es un apóstol de lo incondicional? En el sentido mismo de apóstol, es decir, aquel que camina siempre tras algo o alguien, en este caso de lo incondicional o de lo imposible.

M.C.: En principio, es preciso saber que esta idea tan potente de la hospitalidad incondicional se presta a muchas caricaturas, frecuentemente opuestas, utilizadas contra Derrida para decir que él es el apóstol de una hospitalidad incondicional impracticable. Se dice: “¡Cómo quiere que un Estado no ponga límites a la hospitalidad!”, “¡No podemos acoger a todo el mundo!", etc. Entonces, afirmar que Derrida no es un apóstol de la hospitalidad incondicional es hacer frente a estos resúmenes caricaturescos y peyorativos de su pensamiento que es infinitamente más complejo. Por otra parte, la palabra apóstol le queda mal a Derrida, porque él mismo no habría querido reconocerse como el apóstol de algo, tampoco de la deconstrucción.

Es necesario decir que la oposición entre hospitalidad condicional y hospitalidad incondicional, así como las tensiones que existen entre las dos, expresan la tensión que hay entre el derecho y la justicia que es una tensión aporética, irreconciliable. Esta tensión irreconciliable significa que, en el fondo, el derecho y la justicia pertenecen a órdenes heterogéneos -como la hospitalidad condicional y la hospitalidad incondicional-, no obstante, ello no quiere decir que no haya relación entre ambos. Esto nos recuerda que, sean cuales sean las condiciones que se le impongan a la hospitalidad, éstas no pertenecen al orden de la justicia, ellas no pueden hacerse pasar por la justicia. Esto es lo esencial: la justicia no puede estar nunca del lado de lo condicional. Estas condiciones suponen siempre una transacción con un principio heterogéneo, radicalmente heterogéneo, que es la hospitalidad incondicional y que es del orden de la justicia. Esto hace una enorme diferencia. La diferencia no es entre una hospitalidad condicional y una hospitalidad

Debate publicado en Philosophie magazine, nº 86, Paris, février 2015, pp. 60-65. [Traducción al castellano de Javier Agüero Águila, a publicarse en: Escrituras aneconómicas. Revista de pensamiento contemporáneo, $\mathrm{n}^{\circ}$ 6, Santiago de Chile, primer semestre de 2016]. 
incondicional, hoy día, la diferencia se da entre una hospitalidad condicional que no está en tensión con nada más que consigo misma (y, en este caso, se puede multiplicar al infinito las condiciones, podemos comprometernos con una política que va a hacer cada vez más difícil, cada vez más impracticable la acogida del extranjero) y una política que sabe que las condiciones que impone a la hospitalidad son jurídicas, las que son quizás necesarias, pero que no pueden jamás estar del lado de la justicia.

Es por esta razón que Derrida no es el apóstol de una hospitalidad incondicional que no quisiera saber nada de las condiciones de la hospitalidad condicional. Derrida es alguien que recuerda a los Estados y a las condiciones que le imponen a la hospitalidad, que éstas no pueden ser del orden de la justicia, porque la única justicia posible sería la de una hospitalidad incondicional. Desde el momento en que hay condiciones, no estamos más en el terreno de la justicia, sino en una transacción imposible con su principio.

No es la primera vez que debato con Alain Finkielkraut sobre esta cuestión. Yo fui invitado a la famosa emisión de la mañana del sábado para debatir sobre Europa con un filósofo de derecha muy radical, muy extremista y que, conociendo mi vínculo con el pensamiento de Derrida, me acusaba de una manera muy caricatural, preguntándome cómo podía interesarme en este apóstol de la hospitalidad incondicional, irrealista, que quisiera que los Estados renunciaran a toda regla concreta, a toda norma para regular la acogida a los extranjeros. Entonces, comencé a explicarle que la posición de Derrida era mucho más compleja que eso, y que no existe hospitalidad incondicional que sea pensable independientemente de su tensión con las reglas de la hospitalidad condicional propia de cada Estado.

J.A.: El apóstol es el que camina tras algo; decir que Derrida no es el apóstol de la hospitalidad incondicional puede conducir a creer que él no camina tras la hospitalidad incondicional.

M.C.: El apóstol no se define solamente de esa manera. El apóstol es aquel que lleva el mensaje del Evangelio, es el que anuncia la buena nueva -y no hay buena nueva. Me niego a pensar que un filósofo pueda ser el apóstol de algo, incluso si existen algunos filósofos que se creen apóstoles. Comprendo que ustedes hagan la pregunta. Yo mismo me la he hecho, porque si Derrida no es el que anuncia la buena nueva, él juega todo el tiempo con dos categorías muy próximas, indisociables de la idea de anuncio: la de promesa y la de mesianicidad sin mesianismo. Todo su pensamiento de una democracia por-venir anuncia un acontecimiento por-venir, un acontecimiento que proviene del futuro y cuya estructura depende de esta lógica de la mesianicidad sin mesianismo. Sin duda, todo esto no sucede sin un vínculo (posible) con la figura del apóstol. Sin embargo habría que preguntarse sobre el estatuto de aquel que anuncia esta democracia por-venir, ¿acaso él la piensa solamente? O ¿la anuncia como profeta?, ¿la defiende como apóstol?

Lo que es verdad es que la idea de una democracia por-venir es absolutamente indisociable de la relación entre hospitalidad condicional y hospitalidad incondicional. La democracia por-venir es una democracia que porta una idea de la justicia que incorpora la idea de una hospitalidad incondicional. 
V.G.: En su libro La vocation de l'écriture, publicado el año 2014, sostiene que existe una violencia inscrita en el corazón de la experiencia del lenguaje, es decir, una especie de violencia constitutiva del lenguaje que se aprende en la familia, en la escuela, en el sistema educativo en general y en el medio social. Usted hace la diferencia entre diversas formas de esta violencia. La más radical de ellas sería la que procede de todas esas caracterizaciones indebidas que reducen al otro a cualquier forma de pertenencia o de identidad colectiva o comunitaria, porque borran y anulan su singularidad. Usted alude a los fenómenos del racismo y del antisemitismo, pero nos parece que quiere, de una manera más amplia, apuntar a una violencia inscrita en el lenguaje como instancia general. Sin embargo, sostiene igualmente que es el lenguaje mismo el que nos ofrece la posibilidad, si no de superar, al menos de contradecir esta violencia. Usted se refiere entonces a otra experiencia del lenguaje, a saber, a la del acontecimiento posible de una contra-palabra que responda a la violencia mediante la invención de una singularidad. Usted encuentra esta posibilidad en la literatura y en la filosofía en la medida en que, pasando por la experiencia de la violencia, afirman lo que usted llama "una invención 'idiomática' de la singularidad".

Nos gustaría que desarrollara este último punto, pero, sobre todo, quisiéramos plantearle la siguiente pregunta: considerando el seminario que dicta en l'ENS titulado Contrer la violence, ¿podríamos imaginar un discurso político que rechazara la violencia inherente a su lenguaje, cuando esta misma violencia es constitutiva de la política?, si seguimos lo que usted mismo ha escrito: "Toda política supone la pertenencia, circunscribe la vinculación e impone la exclusión, bajo una forma determinada que, necesariamente, porta la violencia" ${ }^{2}$.

M.C.: En primer lugar intentaré responder a la cuestión del vínculo consubstancial entre violencia y lenguaje. Lo que quise recordar en la larga introducción de La vocation de l'écriture es que en la génesis de toda subjetividad hay un lazo entre la experiencia de la violencia y la experiencia del lenguaje. Primero, porque el aprendizaje del lenguaje, bajo todas sus formas, no se realiza sin violencia, sin coacciones, no se produce sin la asimilación de un cierto número de leyes que rigen su práctica y su uso y que son, en sí mismas, violentas. Cuando hablamos, nos hacemos violencia. Existe lo que queremos decir, lo que no queremos decir, lo que nos atrevemos a decir, lo que no nos atrevemos a decir, lo que no llegaremos a decir; entonces mil y una experiencias que dan cuenta de este lazo tenue y sutil entre la experiencia del lenguaje y la experiencia de la violencia. Se crece con, se vive con, y podemos incluso decir que uno de los principales desafíos de la existencia es tener una relación con el lenguaje que lo libere de la violencia. Esto es, sin duda, la primera, las más general y la más fuerte definición de ética. La ética es la invención de una contra-palabra en la relación con el otro que la libere de la violencia.

2 Marc Crépon, "La peur des étrangers" en: La culture de la peur, I. Démocratie, identité, sécurité, Paris, Galilée, 2008, p. 117. 
¿Cuál es aquí el lugar de la política? ¿A qué se debe el vínculo consubstancial entre política y violencia? En primer lugar, a que toda política es exclusiva desde que está circunscrita en los límites de un Estado determinado. Una política determinada produce, entonces, siempre la exclusión. Luego, el lenguaje político, la lengua que habla la política misma es una lengua que, de manera más o menos visible y sensible, está habitada por la violencia. Incluso los regímenes democráticos, que parecen ser los más alejados de la violencia, no escapan a esta relación constitutiva entre violencia y política. Entonces, frente a la política se impone la necesidad de una contra-palabra. Una de las tareas indispensables de la filosofía es la crítica. Es por esto que los filósofos no deben interesarse únicamente en lo que dicen y escriben los filósofos, sino también en las lenguas múltiples de la política para dar cuenta de la violencia que hay en ellas y que no es siempre explícitamente visible. Pienso que esta es, ciertamente, una de las fuerzas de la deconstrucción en el sentido derridiano, es decir, buscar en los usos del lenguaje -incluido aquí los usos políticos- esta violencia constitutiva.

V.G.: Según su opinión, ¿esta contra-palabra debe permanecer fuera del espacio político?

M.C.: No, no necesariamente.

V.G.: ¿Es posible una contra-palabra en política?

M.C.: Sí, cuando las políticas heredan la violencia, les corresponde imaginar una lengua pública común que saque a la política de esta violencia.

Las grandes escenas de reconciliación y de perdón, por ejemplo, son situaciones que intentan imaginar una lengua común que salga de la espiral de violencia en la que el discurso está encerrado. En mi seminario vamos a trabajar Martin Luther King y Nelson Mandela, la lucha por los derechos civiles y las luchas contra el apartheid. Intentaré mostrar allí los diferentes elementos de lenguaje que proponen Nelson Mandela y Desmond Tutu para sacar a la política de su encierro en la violencia. ¿Cómo salir de la violencia?, esto es lo que me interesa. ¿Cómo el discurso político puede (y debe) dejarse cuestionar, alterar, estremecer por principios heterogéneos como los de la ética? Encontramos un ejemplo de esto en la tensión entre hospitalidad condicional y hospitalidad incondicional de la que hemos hablado. Otra manera de pensar la oposición que hemos descrito consiste en que ella distingue una política de la hospitalidad que no quiere dejarse trabajar por ningún principio ético, de una política que, por el contrario, acoge en ella sus inyunciones.

Para hablar de cosas más concretas, a saber, ¡la crisis mayor de refugiados en Europa! Existen asociaciones que trabajan para acoger a los refugiados, para hacerse cargo de ellos y para ayudarlos a cumplir las formalidades necesarias; asociaciones que luchan por imponer, a situaciones terribles, reglas que no son las de la política, y que están inspiradas por principios éticos fuertes (solidaridad, fraternidad, generosidad, respeto por la dignidad). Entonces, lo que las caracteriza es su anclaje ético. Existe una diferencia enorme entre pensar que todos estos principios deben ser tomados en consideración o pensar a la inversa. Hay una diferencia entre creer que la acogida de 
los refugiados debe obedecer a un imperativo ético que inspire la acción y el discurso, y considerar, por el contrario, que este es un problema técnico y político que debe ser reglado fuera de toda consideración ética (de fraternidad, de solidaridad, etc.).

V.G.: Quisiera insistir sobre la cuestión de la contra-palabra en la literatura y en la filosofía que son lugares exteriores a la política. ¿Es posible pensar esta contra-palabra como una condición de posibilidad para la política?

M.C.: En todo caso, para una política democrática. Es preciso mantener todos los hilos juntos. Si hablamos de la democracia por-venir, esto es otra democracia, atravesada por una idea de la justicia. Ella supone, cada vez, lo que Derrida llama una invención idiomática. No podemos separar el motivo de la democracia por-venir de la hospitalidad incondicional, de la traducción, del idioma, todo esto se une, se articula. Estoy convencido de que otra democracia supone la invención de una contra-palabra. Hoy en día es tan difícil expresarse sobre la cuestión del extranjero, sobre la cuestión de la acogida a los refugiados, y tenemos necesidad de inventar una contra-palabra, por ejemplo, en torno a la cuestión de la inmigración. En esta línea, el libro fundamental es El monolingüismo del otro. Se trata entonces de extraer implicaciones políticas más allá de las que Derrida mismo extrae.

V.G.: Si una contra-palabra es en alguna medida una condición de la democracia, entonces la democracia y la política no son la misma cosa.

M.C.: En el fondo, todo esto consiste en no estar satisfecho con las condiciones actuales de ejercicio de la democracia, todo esto consiste en decirse que la democracia tal como es practicada hoy en día no es la democracia. Es la democracia y no es la democracia al mismo tiempo, no es necesario llamar autoritario a aquello que no lo es. Sin embargo, es realmente crucial separar la idea de democracia como promesa de su ejercicio concreto actual. Es esta disyunción la que es producida por la deconstrucción, cuyo gesto consiste en no encerrar a la democracia en el marco en el que ella está ya instituida y constituida.

V.G.: Jacques Rancière sostiene que la democracia no es un régimen gubernamental, pero concibe la política como democracia.

M.C.: Esto es muy molesto, porque su esquema no permite distinguir la democracia de otros regímenes políticos. En un libro que escribí hace algunos años, Elections, hay un largo capítulo donde yo discuto con Rancière, Badiou y Stiegler, a esto dedicaré mi seminario del próximo año, que tratará sobre la articulación entre ética y política como puesta en juego de la democracia.

J.A.: En relación con los inmigrantes, lo que parece ser interesante en la actualidad es el rol que ha jugado Alemania, ¿cree que Alemania se ha transformado en una especie de ejemplo para Europa a propósito de la apertura que ha tenido con los refugiados? 
M.C.: Lo cierto es que Alemania se ha visto muy sola al momento de enfrentar este gran flujo de refugiados. Es verdad que por razones relacionadas con la natalidad, Alemania tiene necesidad, más que otros países, de esta población de inmigrantes. Pero habría que decir también que ella ha salvado el honor de Europa, abriendo sus puertas ahí donde tantos otros países las han cerrado. Ahora bien, hay que confesar que esta crisis hizo volar en pedazos el sueño europeo. Además, es dramática y consternante la reacción de las poblaciones europeas, la que se ha traducido en un aumento de la xenofobia, del nacionalismo, de los repliegues identitarios. ¡Esto es lo que fragiliza considerablemente a Europa, lo que ella puede representar, lo que puede simbolizar! Es probable que si desde el inicio no hubiéramos dejado sola a Alemania, la reacción de las poblaciones europeas sería, en parte, diferente.

París, 10 de noviembre de 2015 